\title{
專
}

\section{新中國的科蛪研 究”}

\section{李四光}

主席，謵位來賓，諸位代表：

在報告科學院的情况以前, 請放位伐表注意 到中國人民政治協商會議共同網領第江章第四十 一悠至第四十四條, 特别是第四十一集和四十三 蓧的規定。第四十一焂說：“中龩人民共和國的交 化数育等新民主主義的即民族的、科學的、大案的 文化数育。人民政府的文化教育工作，應以提高人 民文化水本，培䅈國家建設人才，廂清封建、買辦 的、法西斯主皒的思想，發展第人民服矤的思想 第主要任務。”第四十三焂說：“努力發展自然科

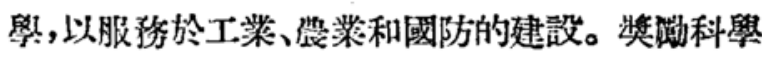

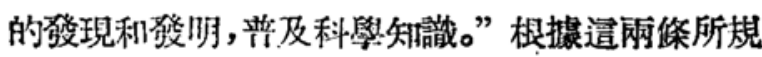
定的基本政策，政務院文化教育委員會郭主任委

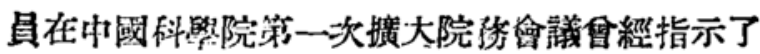
中國科學院基本任務。造程基本任務大致的可以 分暘三方面貺;

一、科學研究方向的碓立

(1) 碓定科學研究俘人民服称的觀點, 與费

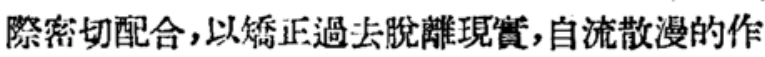
風。

(2)根據近代科學研究發展的接勢, 並吸收 國際焦步科學的經驗, 作凅計劃的理論及筫驗的 研究，以期䞨上閥際學術水平。

(3) 强該科學研究的計割性與集體性, 以加 强各學科研究間有機的聯繁。

二、科學研究人才的培餋與合理分配

(1)加强研究人員的政治學習, 倅能把握黑 列主淁的䚋點與方法。

(2)與各大學及其禁門人才訓練機構聯系,

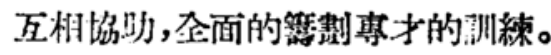

(3)調查全國科學人才, 作有計剩的分配與 補充。

(4)躆召並協助留學國外的科學研究人才返 回竡國工作。

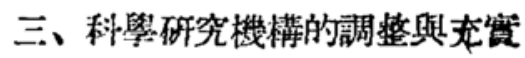

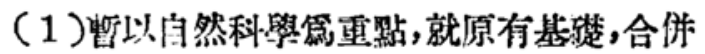
性質相京, 而過去互不相謀的研究機構, 並逐步加 以充望。

(2)展泛的徵求國家剘称工作機構的意見， 並與之建立密切的聯薮以便隨時按照图家當前建 設工作的望際需要, 整定各學科研究工作的重點, 建立地方工作站, 集中力量, 解决筫際問題。

(3)於國家建設有急切需要, 而㗬前份㷛工 作基礎的學科, 擬有計劃地逐步加以砳究。

從這些基本的任㫽, 我們很容易看归來中國 科學院的性犋和過去若干科學研究機檴, 在表面 上踓有若干共同之晴, 但基本上却有很多大不相 同的地方。簡單的說: 過去與中國科學院相類似的 研究機满, 例如中央研究院、北京研究院等, 多牛 只是湴重各倜人的研究工作, 不一定㫨保人民服

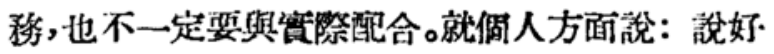
一點, 叫做埋頭苦幹; 說老赛一點, 不免是自仙自

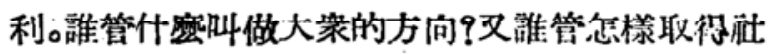
會的聯繁？有時候也有人抄裂了歌美科學家的末

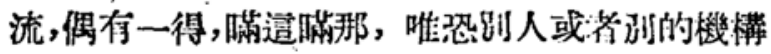
偷去他的琴贵秘密, 或者安自吹複, 以筑那是大不 得了的科學上的貢㱆。

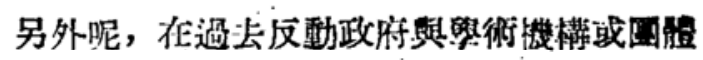

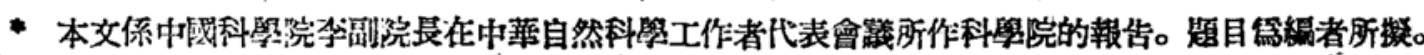


之閔，常常是䯘節的、對立的。反動政府方面之所

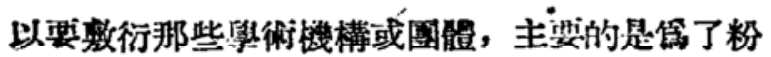
飾門面。而在學術機構或團體方面, 往往用 “學術

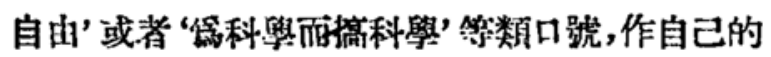
鼠符, 因傦造樣的護符, 對於反動的統治階級有相

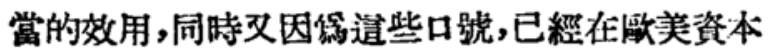
主㼁國家流行已久, 大家連科學工作者本身他在 內, 也就把造種観念賞作䕀高的理想了。其結果不 但是學術注會和他所在的整偑吩會脫離, 而且受 政府㨁接支配的舉術機構和人民所組織的學術團

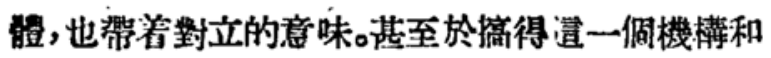

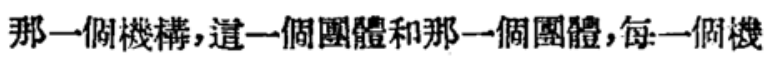
構的䄐一部份和那一部份, 逗一個人和那一倜人,

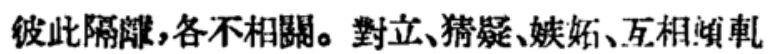
的風载，就是造溙長成的。

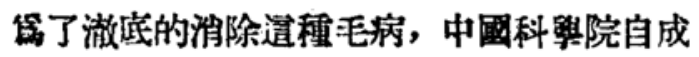
立以來, 就着手在現今一般壯况所允許的一切措 施, 以求團結全國科祭界共同逐步完成上面所說 的任称特别是第一第一、三阿项,第二條以及第 三佟第二項等所指明的任務。因点時間的限制, 現 在只能把已經好的, 正在主和和就要辡 的若干有關事项。分第四類就一倜大要:

第一類是關於專門委員的骋任和敒移。第了 傋量把科學院作成一個全图科學界共同的面同時 在學術工作上带着領導性的機構, 所以就不能不

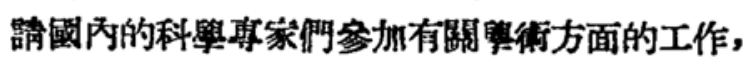
不管所請的各位專家經常是在院內或者院外工 作。自然因䈍受了種程限制, 我阿不能邀請所有専

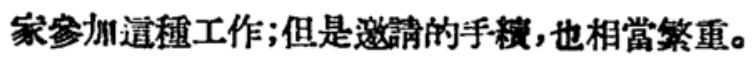
經過的情形大致是通樣的：在一九四儿年十二月 科舆院已經亚始自然科學各學科專家的調查推蔍

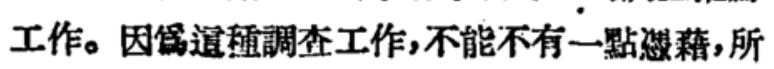
以第一步就用了前中央研究院院士名單, 再經過 選摆和補充就决定了三十五位投票人，請他們分 别在他們所專長或热悉的學科中推藏数人到二十 人的專家名單, 被推葴的専家共二百三十三人。因

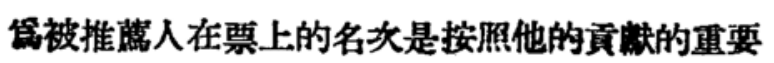
性湎排列, 所以經過珫計,我们造能對每一事家在 某一算科中所佔的相對地位, 有一個估計。㵝了在

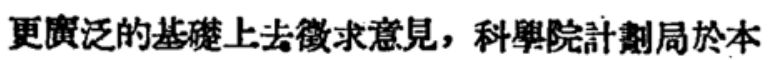
年三月初開始第二次調查, 造次投票人的名單, 是

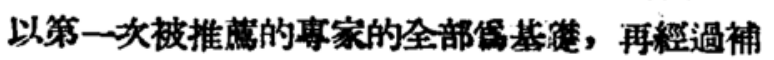

态推蔍的方式與第一次同, 結果被推軳的人共八 百六十五人, 其中一百七十四人還在國外(約佔百 分之二小)。在遗八百六十五人中科學院根據其所

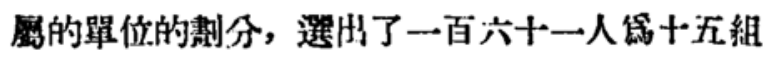

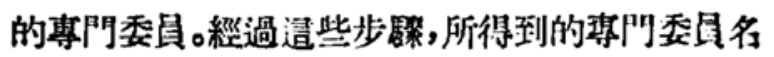
單, 令我們感覺到也還不能包括了所有應㚊邀請

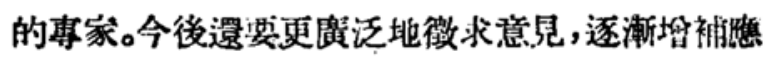
該邀請的專家。

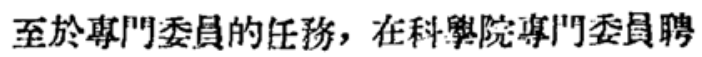
任整行規程第二條已梳得很明白, 就是各種學科

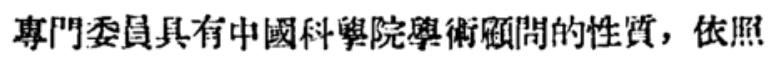
學科的性畝可分第溚干組, 得被商請研討下外各 事项:(一)中國科學院各研究部闍的工作汁制, 執

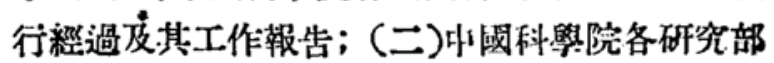
門的高級研究及技術人具的䛣任和哲級；(三)中 國科藇院與院外研究工作的合作; (四)中國科學 院對院外的各棲舉術補助; (五.)科學發現發明和 著作的審核; (六)國際學術合作的策進。其中關於 學術的審議以及審查科學著作的工作尤其重要。 因俘壝種悉議和審查的結果, 不獨對於院內高䄲 研究人員的㧍任和進級等閣題, 具有相當的决定 性, 而且關於科學院在全國以及外國種程科舉上 的活動, 多少也姴取决於此的。從逼些烧定我們很 可以看所來曹門委員在科學院裹佔如何重照的地 位。

第二類是科㮂院聯絡局主要的工作：根㨜大

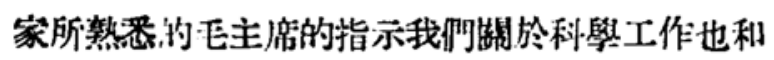
文蓺工作一核, 必須在普及的基礎上提高, 在提高 的指䢘下普及。因此,科學院在各專門擧會協助之 下辩了下例各事:

(一)舆乵了第一期科舉講座。由各然會推嵒 了二十八位主膵人, 共有二十三.個講題, 已縒舉行

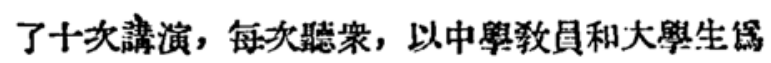
主, 人數平常都在七八百人以上,最少也有三、灼 百人。聽衆方面，亦多熱心，紛紛表示他們的反肤： 如提出設借不够率全, 在玫、理、化、生物旧科均希

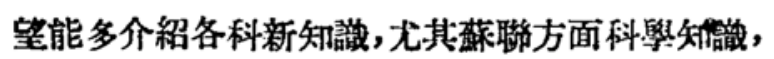
並希望多講些聯繁筧際的問題等等。

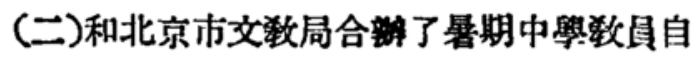
然科學學習會, 运個學習會的聚競, 是根據第一次

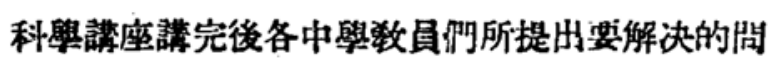

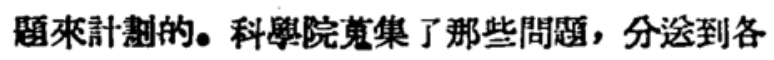




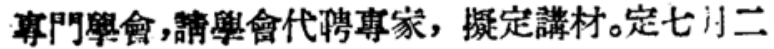
十五日起至八月十五日止第講演的期間。

(三)和國內各大學合作，進行研究工作。合作 的辦法,或者是研究人員的合眝, 或者是研究费用 的補勋和資料的補充, 或者是一部份研究實習員 的培奉，並且我們希望在不久的將來，在可能的笵 图內, 得到一種或幾種的辦法, 使從事高等專門教 育工作者, 和從事婜際技術工作者, 能够在適虽的 期間,利用科學院的設供,進行研究工作, 而在科 學院作了若干年研究工作的人們, 也可以得到僟 會,在適當的期間去呚學生,或者去作葉一些實際 工作。

(ㄴ) 分则邀請國內若干科學專家翏加國際學 術團體集會, 侧如德國科拲院二百五十週年紀念 會、匈京國際数學會等。另外又發列了不少的信 件、電椵,敦促留任成外的中國科學専家，回到租 國服務。又在:本年渡决定派遗留學生十名, 已經政 務院批准，關於被派的人員，也都是經過苔于專門 委員就各方面青年科學工作者推鹤的。

（五)促進對外聯粚，如通過葆聯對外文化協 會及通過外交部, 請向蘇聯及新民主主義國家科

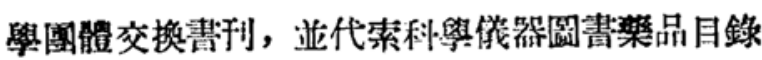
筞。

第三類是關於科學院和望際工作部門的聯繫 工作。在這一方面有幾件事和幾调計劃, 似乎值得 報告一下:

（一)今年春季的應用物理、物理化學、有機化 學各研究所和工程舒縕織了一湖東北訪問團, 到 東北各大工礁中心和科學機構所在哋點，從事各 项訲問和探钨, 在科學院方面和睢經被訪問過的 各方面, 從具體的阔題上, 都能進一步得到了研究 工作和筫際工作必須密河聯慗, 並且雇該如何聯 慗的膫僻。

(二)從上面所說的瞭得, 物理化殞研究所更 進了一步, 準偨把整话的所搬到東北一倠適當的 地點去。

（三)經過一假相嘗哧期的詳細考虑, 科學院 方面, 現在已䋑决定了設地質和沾生物兩储研究 所, 利財經委員會系統下適當的機構取得密切聯 繁。瓷祭從事地質工作人員, 都能取得雨重瓷格, 他們在野外的工作, 由财經方面領導; 在室內的工

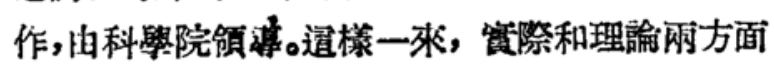

不但是能密切合作, 些且也可以說完全聯合一策 了。

(四)地球物理研究所, 除了經常和莱象局合 作，分析觀测記錄，彆定天策预報以外，還作其他 各項䐴方有關的研究。

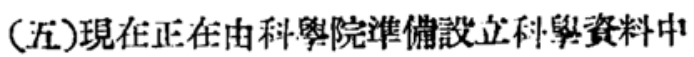
心站, 不但計都供給焦諭住在什麼地方的全國科

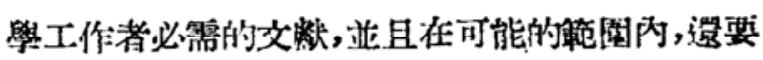

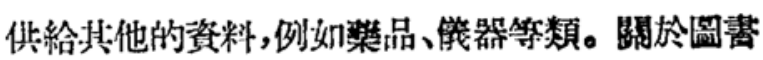

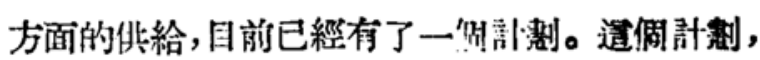

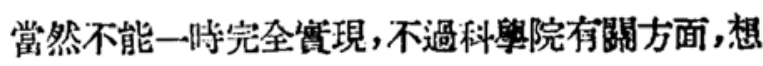

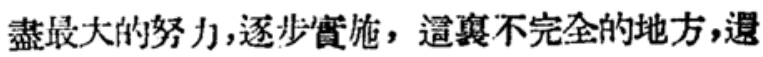
㴗請大家涽示。

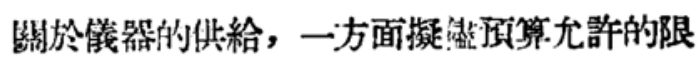

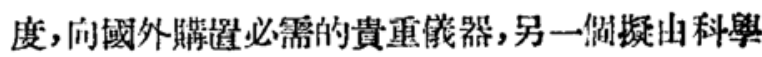
院聯合得生部、呚育部、文化部和其他有關政府的

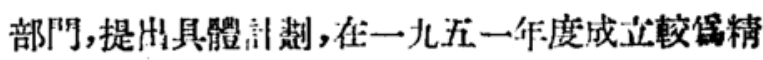
密的儀器工微, 大量製造教育、衛生、科究研究的 工具和器材, 亚且鳌定我們自己的標潐。

第四類是編臎局的工作。道些工作也可以分 幾項涗:

（一)版版本院綜合性的期刊：甲、科學通報： 每月印行一次。赧導本院國內外科學界重態，亚介

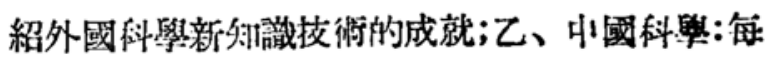
三倜月明版一次,專砤表我國科學家的研究諭文; 两、科學紀錄:愈科學院與國外交換的棕合性等㭪

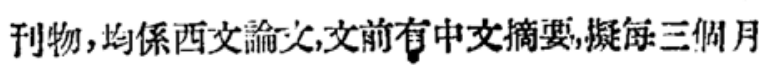
H!版一次; 丁、編印本院所屬各研究機構的期刊。

(二)扶助國內各專門學會及研究會诗版期刊

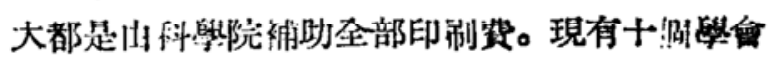
申請補此, 已經决定補助的有七倜擧會。

(三)推勘翻譯工作, 在目前㮖以大學敉課蓄

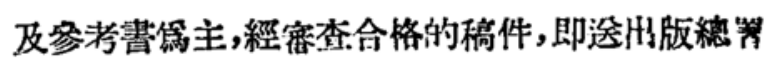
H版, 翻譯的書籍以俄文居多數。

(四)統一科學名詞的編譯工作, 第推讨此项 工作，撽約請一百十八位專家第自然㸯學組各賉 科的科學名詞察查委員。预定在八月底,可以編完 五程學科的科學名詞。

這些措施, 當然不够完傮, 唯其如此, 很希望

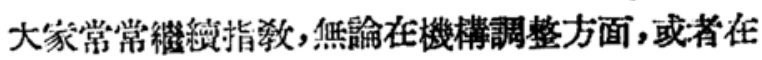

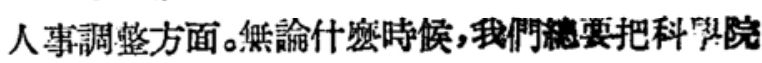

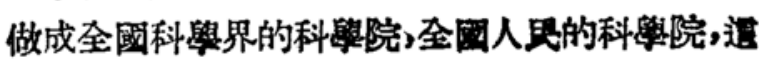


就要靠院內和院外科學工作者一玫的努力, 才能 到。

不需要說, 科祭院最大的任務, 是研究工作, 適應费察需要的研究工作。在現時所能得到的人 力和物資的範国以內, 已經成立了近代史、考古、 語言、嘀會、近代物理、應用物理、地球物理、物理

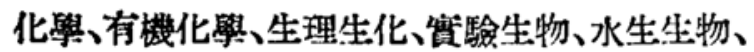
植物分類十三佔研究所; 心理、地理、数學三僻研 究所的籍備處, 和一個天文台, 一倜工程筫驗節。 不久的將來, 就要成立地質和占生物网调研究所。 每一倜單位, 大都分若干研究室, 由研究敉授、研 究員、剧研究員、此理研究員以及望㕷研究員分别 担任研究工作。

退些研究工作單位, 一部份是由嚄有的科學 機粠改造的, 另一部份是新設的。或者由於房屋不 哆分配, 或者由於天然環境的便利, 有些研究所、 研究室、工作站分散在各地, 但是大部份現時都集 中在上海、南京和北京三凮城市。因第利用蕉有的

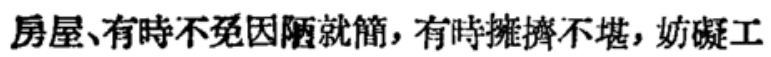
作的開展。造是現階段不可避免的困難,如果我阿 㴔現了我門的工作不够份量, 我们當然不能把原 因完全推到這種困難上去。况且逜稞物質上的困 耕隹,在媵年內，一定可以克服的。

我們要潵底的了解像中國科學院通漛的設 㯰, 不但是在形式上, 例如建築物的表現上, 標誌 着我門埸立自主和創造的精神，並且在筫質上，做 成一個國內和國際的學街中心。這蓇需要一點說 明：在過去中國科舉界可以說是有一倜相當普遍 的毛病, 而當時多数人似乎都汥有覺得它的䈗重 性,那種毛病就是把科學工作的重心㨢在外國。隨 便舉一倜例說吧: 最近三、四十年來, 中國的物理

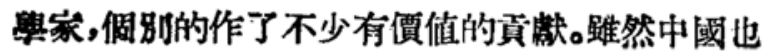
有中國物理學報以及其他有關的專門雜誌, 而在 那七百多篇已經出版了的物理論文中, 就有四百 多篇是分散在外國雜誌上, 說一句外行的話, 恐怕 比較重要的著作，大多數都是在外國墢表的。

在國內踓然也有了一些專門科翼的團體，但 是因绐組織那些園體的成員, 多牛檤接間接受了

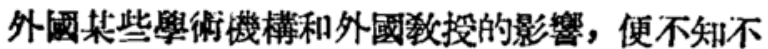
學灾却了在本國建立黃正有摆立性、有創造性的

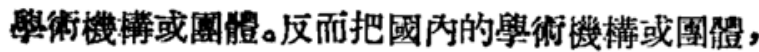

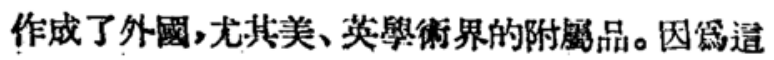

榢, 在中國科藇界, 不资發生一種隘落的心理, 好

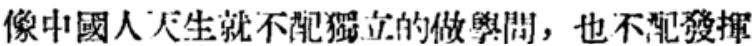
我们固有的佮造能力。选至於外國人所超的錯路, 我門還得跟着走,我们所走龂了的路徑, 不得外國 人的承認, 也就被國內同行的人何抹䓡了。常然我 僻得承認中國近代科祭是一些留學生通接開接從 略美般回中國的。在那種情形之下，我河也很難怪 中國的科學界不染一些融美的息味。但是要做到 像過去那樣把我們自己網死, 㱆身給人家,那就米 㭆㭳牲太大了。

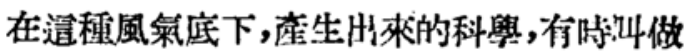
附绷的科學，筫際上比附涟還要壊多了。那些境的 影響, 在帶着地域性的科學上, 更加留管。我們平 心而論, 過去在中國做過帶猈地域性的科學的外

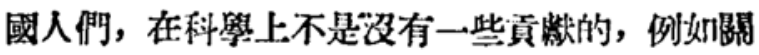
於中國各區域各種動植物椞的零星和較绝有系統 的記载, 在幾橭地方或者沿不幾保路線覞测中國

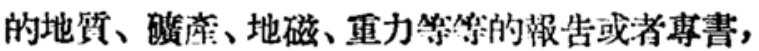
多少都含着䛧得保保的科學资料。但是我們假如 把那些人作這些工作的動機和目的分析一下，我 們若是發現了他們企圖在他们個人的身份上造成

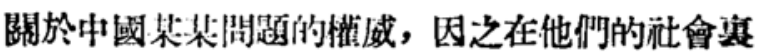
一资柇制度社會一一提高他們侗人的地位; 另

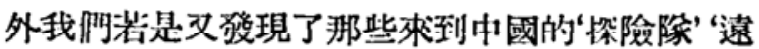

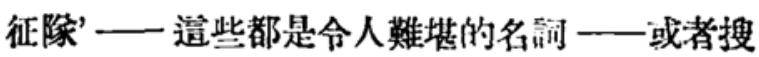
集中國特殊資料的團體或者假人，是受了他們號

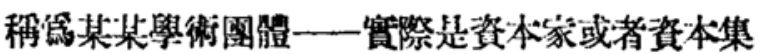
團在後面一谌至於受他們政俯指使的話, 我們

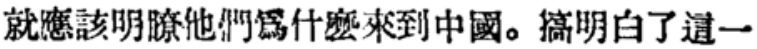

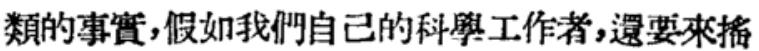

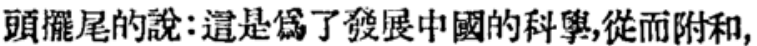
甚至於被他們拖在一起工作, 或者道接間接受他 們的指使而工作着, 那就恐怕不能算是楜管, 而是 睬着雨眼甘心受他們的奴役。

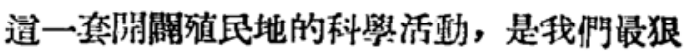
毒的敵人之一, 因琈跟着那等的活動不可避免的

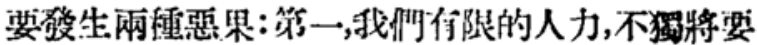

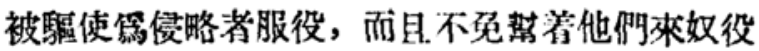
中國人。第二, 在我們自己的上地上，第了建設䍚 古國家和健全的科學工作基礎以及培䓹創造的精

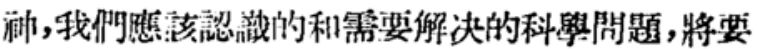

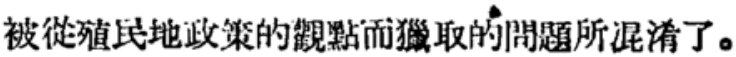




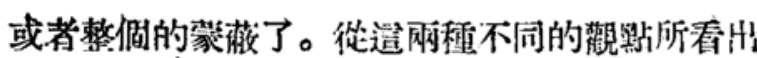

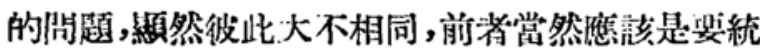
的是正碓的, 而後者必然是片面的、歪曲的。我 們不能允詐通種東西今後在中國的土地上遺留絲 毫的痕跡。這不是說我們一概的反對國際科學合 作,相反的, 我們正要和全世界的科學界合作, 禋 琶它不含着毒性，因第那是另外一回事。

西方科學的進步,到了現今這一階段,無諭就 科學本身說, 或省把科學工作當作人類向上的努

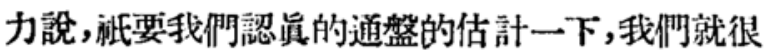
容易發現所謂溥統的觀點, 不能不有基本的變化。 造種基本的變化,幾乎在每一種科學最近三、四一 年來的斎展上都可以看出的。這一個時期正是一 向關在牛封建新會裹、牛殖民地裹, 不大被人看得 起的中國人椚始夾在西方科學家中偑别的做一些 不應該被人抹殺的, 不,有時绻煌的貢獻, 不論在 帶着地方性或者在嶨朴科學,如物理數學方面。現 在我們幾手可以說:整侗掯:統的西方科學,由於它 本身的弹展和资代主淁讷會的崩惯，今天達到了 一個恐慌的階段, 這種恐慌, 甚至於影響到最有客
葙性的物量科學。在其他一連串的基本科學方自，

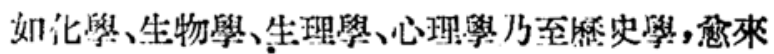

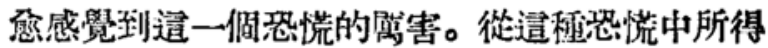
到的新認識, 對於今後世界上各程科舉機構的馒 展, 恐怕不能不有很大的影䈉,我門中國正在萌芽 的各種科學機構,恐怕也不是例外。

從人和自然互相浸透的觀點H䝢, 一直到人 倠有自學性的、有組織的、有秩序的刢造世界,也 就是畺正有科學性的歷史, 開始的階段我們需要 用許多隨科學進展而變更的方式來都分各門科舉 的領域, 改進它的方法, 並且需要随時培食一些缺 乏的專門人才,在每一佔階段,我們總不能脫離望 際社會的狀况一一也就是生產的方式一一就那些 專業科學工作者就各㑬人工作的領域, 在適當的 配合之下, 緊密的聯繋起來工作。那樣, 才能逐步 的發鼠一個有全面性的科學工作計劃，才能改進 生產的方式和效能, 才能使整個社會的結構更合 理化。這當然不是一兩年的事, 而是中國科學院長 期最大的企㕵, 也是最需慗各位給我們以協助的 地方。

\section{中華全國自然科學工作者代表會議全體代表向毛主席致敬}

敬要的毛主席:

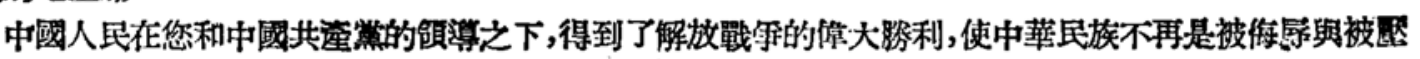
迫的民族而且在成立了不到一年的人民政府，已經做到了財政經沙上初步好轉的局面。我們䜕代表全中國 的自然科學工作者，向您致最崇高的敬差和衰心的感謝。

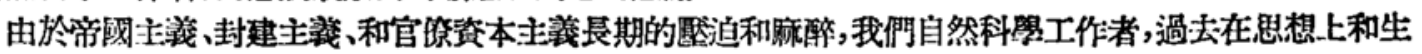

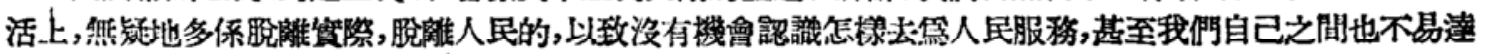
到親密的圈結。

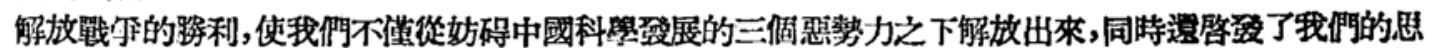

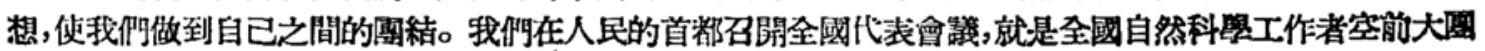
結的表現。

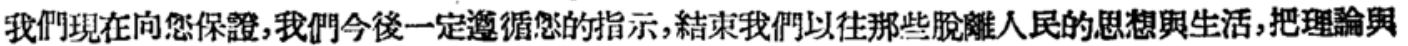

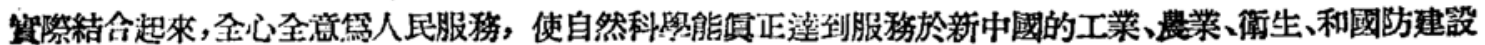

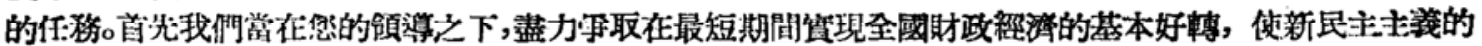

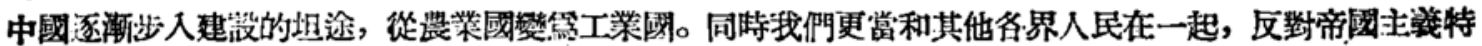
別是美帝主汶﨎於新中國以及其他亞洲人民的侵略, 並進而團結全世界的自然科學工作者, 保衛世界持久和

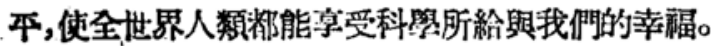

敬视等的

像 康

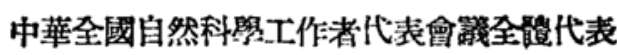

$$
\text { 一九五○年八月二十日 }
$$

